\title{
PERILAKU LESBIAN GAY BISEKSUAL DAN TRANSGENDER ( LGBT ) DALAM PERSPEKTIF HAK AZASI MANUSIA
}

\author{
Anisa Fauziah, Sugeng Samiyono, Fithry Khairiyati \\ Fakultas Hukum Universitas Pamulang \\ E-Mail: dosen00463@unpam.ac.id
}

\begin{abstract}
Abstrak
Perilaku Lesbian, Gay, Biseksual dan Transgender atau dikenal dengan sebutan istilah LGBT adalah fenomena sosial yang sedang banyak disorot masyarakat baik dari nasional maupun internasional. Permasalahannya adalah ketika masyarakat Indonesia tidak mempunyai kesepakatan yang sama tentang kedudukan LGBT di negara ini karena alasan sebuah Hak Asasi Manusia (HAM). Hak Asasi Manusia pada dasarnya mempunyai tujuan agar pelaksanaan HAM sesuai dengan Piagam PBB tentang HAM, UUD 1945, dan Pancasila dapat tumbuh dengan kondisi yang kondusif. Dalam penelitian ini bertujuan untuk menjawab dan mendeskripsikan bagaimana perilaku LGBT yang meresahkan masyarakat Indonesia dan masyarakat internasional secara mayoritasnya. Disamping itu tujuan penelitian ini adalah untuk mendeskripsikan bagaimana tinjauan HAM Nasional dan HAM Internasional terhadap perilaku LGBT tersebut. Metode yang digunakan dalam penelitian ini adalah socio-legal research atau disebut dengan penelitian hukum sosiologis yang mana melihat hukum merupakan gejala sosial yang bersifat empiris dengan menggunakan data primer hasil wawancara dengan MUI, ICMI dan Komnas HAM serta data sekunder yang diambil dari Undang-Undang HAM Nomor 39 Tahun 1999, handbook Komnas HAM, Deklarasi HAM dan handbook UNDP ( United Nations Development Program). Dengan begitu, perilaku LGBT tidak dapat dibenarkan karena tidak ada legalitasnya dan melanggar norma-norma kesusilaan serta berpotensi menimbulkan keresahan di masyarakat. Sehingga apa yang telah diamanatkan oleh Undang-Undang Dasar Negara Republik Indonesia Tahun 1945 tidak dapat terwujud, yaitu menciptakan ketertiban dan keamanan masyarakat Indonesia. Dan menurut HAM Internasional sendiri perilaku LGBT tidak diakui karena dalam Deklarasi HAM tidak ada pelegalan terhadap LGBT dan hanya disebutkan pria dan wanita sebagai pasangan.
\end{abstract}

Kata kunci: LGBT; HAM Nasional; HAM Internasional; UNDP.

\section{Abstract}

Lesbian, gay, bisexual, and transgender behavior, or commonly known as LGBT, is a social phenomenon that is highlighted by many people at national and international levels. The problem is if the Indonesian people do not reach the same agreement on the position of LGBT people in this country for human rights reasons (HAM). Human rights are essentially aimed at developing 
conducive and conditionally to the human rights implementation under the United Nations Charter on Human Rights, Pancasila and the 1945 Constitution. This study has a purpose for providing answers and describing how LGBT behavior is troubling for the Indonesian people and the international community in general. In addition, it will also be examined how international human rights and national human rights regarding LGBT behavior are reviewed. This study uses the legal research of sociological method, in which law is viewed as an empirical social phenomenon, using primary data from interviews with MUI, ICMI and Komnas HAM as well as secondary data from the Human Rights Act number 39 from 1999, Komnas HAM Handbook, Human Rights Declaration and UNDP Handbook (United Nations Development Program). In this way, LGBT behavior cannot be justified because there is no legality, violates decency norms and has the potential to cause unrest in society. This meant that what was prescribed in the Republic of Indonesian's 1945 constitution could not be achieved, namely to create order and security for the Indonesian people. And according to the International Human Rights itself, $L G B T$ behavior is not recognized because there is no legalization of LGBT in the Declaration of Human Rights and only men and women are mentioned as partners.

Keywords: LGBT; National Human Rights; International Human Rights; UNDP.

\section{Pendahuluan}

Di Indonesia perilaku seksual yang menyimpang menjadi suatu hal yang tabu di kalangan masyarakat. Pengajaran agama, moral dan etika masih padat dan dipegang dengan kuat oleh manusia secara umumnya. Tindakan menyimpang secara seksual tentu bukan kejadian yang bisa dengan mudahnya diterima. Tindakan seksual penyimpangan pada dasarnya timbul karena penyimpangan terhadap orientasi seksual. Orientasi seksual merupakan kecenderungan dalam meluapkan perasaan ketertarikan, romansa, emosi, dan seks seseorang kepada wanita, pria, atau campuran keduanya. ${ }^{1}$ Tindakan menyimpang ini dilakukan oleh orang atau kelompok yang mempunyai perbedaan orientasi seksual atau biasa disebut dengan kelompok LGBT (lesbian, gay, biseksual dan (transgender / transeksual). Sejak tahun 1990-an istilah

${ }^{1}$ Crews, Douglas., \& Crawford, Marcus. (2015). Exploring the Role of Being Out on a Queer Person's Self-Compassion. Journal of Gay \& Lesbian Social Services Vol. 27 (No. 2), pp. 172-186 
LGBT telah digunakan, sebagai pengganti istilah komunitas gay sebab istilah tersebut dianggap representatif golongan yang secara lebih detail mengisi istilah tersebut. Golongan LGBT terdiri dari : 1) Lesbi: Sekelompok perempuan yang menurut fisiknya, menurut emosional dan / atau mental mempunyai ketertarikan pada perempuan yang lain; 2) gay: sekelompok laki-laki yang menurut fisiknya, emosional dan / atau mental mempunyai ketertarikan pada laki-laki lain; 3) Biseksual: golongan orang yang menurut fisiknya, emosional dan / atau spiritual mempunyai ketertarikan pada sesama jenis dan lawan jenis; 4) Transgender: Golongan orang yang mempunyai perasaan bahwa mereka memiliki perbedaan identitas gender dari anatomi genital. Karena itu pemilihan /non-pemilihan operasi genital disesuaikan dengan keinginan identitas gender. ${ }^{2}$

Pada dasarnya LGBT bukan suatu yang baru di negara Indonesia. Sebelum ini, guna mempertimbangkan kepentingan golongan LGBT, terutama untuk menggaungkan pelanggaran hak-hak mereka sebagai golongan seksual minoritas telah diadakan beberapa pertemuan penting. Pada 2006 di Yogyakarta diadakan suatu pertemuan, di mana pertemuan tersebut diadakan "Prinsip Yogyakarta untuk Menerapkan Undang-Undang Hak Asasi Manusia Internasional Mengenai Orientasi Seksual dan Identitas Gender" telah lahir. Beberapa prinsip ini memfokuskan pada proteksi hak-hak golongan seksual minoritas dan melahirkan cipta kerja untuk standar HAM internasional terhadap komunitas yang mempunyai orientasi seksual dan identitas gender khusus. ${ }^{3}$

Beberapa penelitian telah dilaksanakan oleh para ilmuwan dan aktivis hak asasi manusia, yang mengarah ke polarisasi tindakan kepada orang-orang LGBT. Tindakan seksual menyimpang ini ditolak banyak pihak dan yang menerimanya juga tidak sedikit. Debat tentang pendapat antara keduanya memanas dan diperluas oleh adanya argumen dengan perspektif hak asasi manusia dan argumen dengan perspektif agama. Mereka yang berkomitmen pada perilaku seksual menyimpang, seringkali hak asasi manusia untuk tameng dalam memproteksi kepentingan orang LGBT. Bahwa kaum tersebut merupakan orang-orang yang mempunyai peluang persamaan hak dan dilarang untuk memperlakukannya secara diskriminasi (kriminalisasi terhadap penyimpangan seksual kaum tersebut). Indonesia, di pihak lain, merupakan negara yang berpusat pada Tuhan. Sebagai negara yang mengakui Tuhan, warganya

${ }^{2}$ APA (American Psychological Association). (2015). Definitions Related to Sexual Orientation and Gender Diversity in APA

${ }^{3}$ Onapajo, Hakeem., \& Isike, Cristhoper. (2016). The Global Politics of Gay Rights: The Straining Relations between the West and Africa. Journal of Global Analysis, Vol. 6 (No. 1, January), pp. 22-34. 
diberikan keleluasaan dalam menjalankan perintah-perintah Tuhan, seperti yang tercantum pada ajaran agama masing-masing dan pada tulisan suci. Tidak ada pembenaran yang bisa digunakan sebagai argumen dalam menyetujui dan membenarkan tindakan menyimpang secara seksual oleh orang-orang LGBT menurut agama yang diakui di Indonesia.

Hukum di Indonesia hanya memberikan pengakuan terhadap eksistensi gender pria dan wanita, sehingga orang-orang transgender yang tidak memilih untuk melakukan operasi perubahan jenis kelamin, bisa mempunyai kendala pada administrasi dokumen identitas dan segala hal yang berhubungan dengannya. Beberapa peraturan daerah melarang homoseksualitas dan memasukkannya kedalam kejahatan karena dianggap suatu tindakan tidak bermoral, walaupun empat dari lima Perda yang berhubungan yang secara implisit mengatur hukuman. Hukum dan regulasi di Indonesia hanya menetapkan dua jenis kelamin, pria dan wanita. Hal tersebut bisa ditafsirkan dari penyertaan eksplisit pria dan wanita dalam UU Perkawinan (UU No. $1 / 1974)^{4}$ dan peraturan yang sama tentang isi kartu penduduk yang diatur dalam Undang-Undang Administrasi Kependudukan (UU No. 23/2006). ${ }^{5}$

Instrumen Hukum Hak Asasi Manusia Internasional seperti Deklarasi Universal Hak Asasi Manusia, Kovenan Internasional tentang Hak Sipil dan Politik (ICCPR), dan Kovenan Internasional tentang Hak Ekonomi, Sosial, dan Budaya (ICESCR). membawa perubahan signifikan dalam perjuangan untuk meningkatkan kepedulian semua orang akan pentingnya kemanusiaan. Hak asasi manusia bergantung pada nilai-nilai, tradisi, dan norma yang diterima secara umum, meskipun tidak semua negara memiliki kebiasaan atau norma ini.

Pada tahun 1977, di San Francisco, Amerika Serikat, seorang Pengawas Kota bernama Harvey Milk menjadi orang gay pertama yang menjadi pejabat sipil. ${ }^{6}$ Harvey Milk sangat vokal menyuarakan persamaan hak bagi orang-orang LGBT. Karena keterlibatan aktif Harvey Milk dalam menyuarakan perlindungan hak-hak LGBT, bahkan Provinsi Quebec di Kanada menjadi provinsi pertama yang melarang diskriminasi berdasarkan orientasi seksual. Namun, perjuangan Milk menuai hasil yang pahit, karena setahun setelah itu Harvey Milk dan Walikota San Francisco pada waktu itu, George Moscone terbunuh atas dasar mempromosikan hak-hak LGBT di wilayah San Fransisco. Setelah era Harvey Milk, penerimaan LGBT masih mengalami pro dan kontra. Di beberapa negara di dunia, keberadaan orang LGBT sangat dilarang oleh hukum yang berlaku di

${ }^{4}$ Undang-Undang Nomor 1 Tahun 1974 tentang Perkawinan

${ }^{5}$ Undang-Undang No. 23/2006 Tentang Administrasi Kependudukan

6 The Biography Channel Harvey Milk. (http://www.biography.com/people/harvey-milk-9408170) Diakses pada 11 Desember 2013. 
negara itu. Di Iran dan Afghanistan, hukuman mati dijatuhkan pada warga negara yang ditemukan terlibat dalam hubungan sesama jenis. ${ }^{7}$

Di Zimbabwe, Presiden Robert Mugabe membuat pernyataan tentang keberadaan orang-orang LGBT di negaranya bahwa hewan di hutan adalah lebih baik daripada orang-orang ini (hewan di hutan lebih baik daripada orang-orang ini) dan homoseksual lebih buruk daripada anjing dan babi (homoseksual lebih buruk daripada anjing dan babi) . Pada akhir 2012, Kremlin atau Rusia legislatif mengeluarkan undang-undang yang melarang "propaganda homoseksual" dan peraturan ini sudah mulai diterapkan di sembilan provinsi di Rusia. Semua bentuk kegiatan pro-homoseksual seperti bendera pelangi atau logo dianggap "propaganda" yang melanggar peraturan dalam negeri Rusia.

Peraturan ini mengundang protes dari aktivis hak LGBT di Rusia yang kemudian menyelenggarakan demonstrasi di tengah kota Petersburg, ibukota Rusia, tetapi demonstrasi ini ditentang oleh pemerintah daerah dan beberapa aktivis yang berpartisipasi dalam demonstrasi ditindas oleh pejabat pemerintah yang kemudian memenjarakan mereka. Bahkan ketika penulis menyelesaikan tesis ini, negara India sekali lagi membuat peraturan yang mengkriminalkan homoseksual, dan negara Uganda mengeluarkan peraturan yang mengkriminalkan orang LGBT disebut Anti-Homoseksualitas Act 2014 dimana kegiatan mempromosikan, mendukung atau terlibat dalam seks sesama jenis dapat dijatuhi hukuman penjara dan bahkan hukuman mati.

Pentingnya penerimaan komunitas internasional terhadap keberadaan dan perlindungan hak-hak LGBT perlu ditekankan karena instrumen hukum hak asasi manusia internasional menjamin hak asasi manusia dan kebebasan mendasar seperti hak untuk tidak memiliki hak untuk mengekspresikan pendapat secara bebas, ${ }^{8}$ hak untuk tidak secara sewenang-wenang ditahan ${ }^{9}$ dan hak untuk bebas dari penyiksaan. ${ }^{10} \mathrm{Hampir}$ semua negara di dunia telah menandatangani dan meratifikasi konvensi hak asasi manusia yang mengatur hak dan kebebasan sebagaimana disebutkan sebelumnya yang tentu saja merupakan hak dasar setiap orang termasuk orang LGBT.

\section{Permasalahan}

Sesuai dengan latar belakang masalah yang sudah dijabarkan di atas, dengan ini penulis mengambil inti permasalahan yang berupa pertama,

${ }^{7}$ The Huffington Post. Robert Mugabe, Zimbabwe President, Threatens To Behead Gay Citizens. (http://www.huffingtonpost.com/2013/07/26/mugabe-zimbabwe-behead gays_n_3659454.html) Dikunjungi pada 11 Desember 2013.

${ }^{8}$ UDHR. Pasal 19; ICCPR. Pasal 19; ECHR. Pasal 10; African Charter. Pasal 9.

${ }^{9}$ UDHR. Pasal 9; ICCPR. Pasal 9; ECHR. Pasal 5; African Charter. Pasal 4.

${ }^{10}$ UDHR. Pasal 5; ICCPR. Pasal 7; ECHR. Pasal 3; African Charter. Pasal 5. 
Bagaimana perilaku LGBT ditinjau dari perspektif HAM Nasional ? Kedua Bagaimana perilaku LGBT ditinjau dari perspektif HAM Internasional ?

\section{Metode Penelitian}

Penelitian ini menggunakan metode pendekatan hukum sosiologis (socio-legal research), yang memandang hukum sebagai gejala sosial yang bersifat empiris, ${ }^{11}$ dengan bentuk deskriptif yang bertujuan menjelaskan tentang LGBT ditinjau dalam HAM Nasional dan HAM Internasional serta pengaruh perilaku LGBT terhadap masyarakat Indonesia khususnya.

Menganalisis data secara kualitatif-empiris, menelaah dan menafsirkan untuk menjawab masalah penelitian. Metode analisis kualitatif, menurut data sekunder yaitu teori, arti dan isi dari berbagai literatur, peraturan perundangundangan. Sedangkan memperoleh data primer dari hasil wawancara (interview) di lapangan baik secara langsung maupun tidak langsung.

\section{Pembahasan}

\section{Lesbian Gay Biseksual dan Transgender dalam Perspektif Agama dan Hak} Asasi Manusia Nasional

Manfred Nowak menyebutkan bahwa prinsip hak asasi manusia ada empat yaitu, universal (universality), tak terbagi (indivisibility), saling bergantung (interdependent), saling terkait (interrelated). ${ }^{12}$ Prinsip universal pada dasarnya menyatakan dimana semua orang di dunia mempunyai hak yang sama untuk eksistensi orang itu sendiri. Prinsip tak terbagi berkaitan dengan tidak dapatnya hak asasi manusia dibagi dengan hak-hak tertentu dan semua hak asasi manusia sama-sama penting. Sedangkan prinsip saling bergantung dan saling berhubungan merupakan hak- hak yang satu akan selalu bergantung dengan terpenuhinya hak yang lain dan tidak dipisahkan dari yang lain. Oleh karena itu, setiap hak perlu adanya pembatasan terhadap hak-hak manusia lainnya ketika berpotensi menimbulkan kegaduhan dan ketertiban masyarakat. Demikian halnya dengan perilaku LGBT.

Di Indonesia sendiri terdapat pro dan kontra dalam memandang perilaku LGBT tersebut. Ketika manusia mengkaitkan LGBT dengan agama, secara otomatis perilaku LGBT bertentangan dengan semua norma-norma agama yang diakui di Indonesia. Tiada suatu agama pun di Indonesia yang menyatakan persetujuannya dan dukungannya terhadap perilaku LGBT. Hal ini dapat kita ketahui dari Fatwa Majelis Ulama Indonesia (MUI) Nomor 57 Tahun 2014 tentang

${ }^{11}$ Amiruddin dan H.Zainal Asikin, 2004, Pengantar Metode Penelitian Hukum, PT Raja Grafindo Persada, Jakarta, hlm. 133-134.

${ }^{12}$ Manfred Nowak, Introduction to The International Human Rights Regime, Martinus Nijhoff Publishers, Leiden, 2003, hlm. 27. 
Lesbian, Gay, Sodomi, dan Pencabulan. ${ }^{13}$ Fatwa ini menegaskan bahwa aktifitas dan tindakan LGBT diharamkan sebab merupakan salah satu bentuk kejahatan. Sehingga dengan adanya Fatwa MUI tersebut yang notabene adalah representatif dari negara di bidang keagamaan menguatkan akan hal dilarangnya dan tidak diakuinya LGBT di Indonesia.

Tentu hal tersebut tidak serta merta disetujui dan disepakati oleh masyarakat Indonesia terutama oleh para aktivis hak asasi manusia. Jika kita melihat istilah hak asasi manusia, yang membela gagasan dan nilai-nilai manusia dan diterapkan secara menyeluruh, sepertinya dengan ini hak asasi manusia bergema di semua budaya dan tradisi. Oleh sebab itu, hak asasi manusia adalah panggilan krusial untuk orang-orang yang mencari perdamaian dan keadilan secara terus menerus di dunia. ${ }^{14}$

Dalam Undang-Undang Nomor 39 Tahun 1999 mengatur tentang hak asasi manusia. Pembatasan hak asasi manusia telah diatur ketentuannya dalam undang-undang tersebut. Diantaranya adalah Pasal 73 (c) Undang-Undang Nomor 39 Tahun 1999 bahwa pembatasan hak asasi manusia boleh dilakukan dengan alasan penghormatan terhadap kesusilaan, ketertiban umum dan kepentingan bangsa. Kemudian dalam Pasal 28J ayat (2) c Undang-Undang Dasar Negara Republik Indonesia Tahun 1945 , menyatakan bahwa pembatasan hak asasi manusia dapat dilakukan dengan alasan memenuhi tuntutan yang adil sesuai dengan pertimbangan moral, nilai-nilai agama, keamanan, dan ketertiban umum dalam suatu masyarakat demokratis. ${ }^{15}$

Komisi Nasional Hak Asasi Manusia (Komnas HAM) sendiri berpendapat bahwa orientasi seksual merupakan hak asasi manusia seseorang. Oleh karena itu Komnas HAM merasa LGBT berhak untuk melakukan kebebasan orientasi seksualnya. ${ }^{16}$ Tentu pendapat Komnas HAM tersebut sangat bertentangan dengan UUD 1945 dan substansi yang terdapat pada butir-butir Pancasila. Orientasi seksual yang seharusnya dan selazimnya adalah orientasi seksual antar pria dan wanita, bukan orientasi seksual terhadap sesama jenis. Ketika seseorang itu melakukan orientasi seksualnya dengan sesama jenis maka dapat menimbulkan keresahan dalam masyarakat. Termasuk juga melanggar nilai-

${ }^{13}$ Fatwa MUI Tentang Nomor 57 Tahun 2014 Tentang Lesbian, Gay, Sodomi dan Pencabulan, diakses dari internet pada tanggal 16 Juli 2020 pukul 8.38.

${ }^{14}$ Meilanny Budiarti Santoso, "LGBT Dalam Perspektif HAM", dalam jurnal Share Social Work Journal, 229 (2016).

${ }^{15}$ Eko Riyadi, Hukum Hak Asasi Manusia Perspektif Internasional, Regional dan Nasional, Rajawali Pers, Depok, 2018, hlm. 60.

${ }^{16}$ Komisi Nasional Hak Asasi Manusia, Prinsip-Prinsip Pemberlakuan Hukum HAM Internasional Dalam Kaitannya Dengan Orientasi Seksual dan Identitas Jender, Komnas HAM, Jakarta, 2015, hal.2. 
nilai agama dan moral seperti yang telah dijelaskan dalam Pasal 28J ayat (2) C Undang-Undang Dasar Negara Republik Indonesia Tahun 1945.

Keberadaan LGBT movement di Indonesia adalah suatu dinamika dari salah satu keragaman gaya hidup. Ada dua hal yang menjadi tuntutan aktivis dan pelaku LGBT, yaitu terbebas dari tindakan diskriminasi (meliputi keabsahan perkawinan sesama jenis). Kekerasan yang sering terjadi pada kaum LGBT tersebut dikarenakan pemerintah dalam menegakkan hukum dianggap lemah. Padahal, setiap warga negara seharusnya dilindungi pemerintah menurut pada berlakunya regulasi. Sebaliknya, pelaku LGBT yang ingin mendapatkan legalisasi perkawinan sangat berlawanan dengan aturan hukum yang ada dan berlaku di negara Indonesia.

Banyaknya kejahatan yang terjadi dilakukan oleh pelaku LGBT dan banyaknya kasus HIV tentu saja sangat meresahkan masyarakat. Orang tua pasti tidak ada yang menginginkan keturunannya menjadi pelaku dan anggota LGBT dan tentunya berikhtiar mendidik dan membangun sifat dan tabiat yang baik dalam perkembangannya. Berdasarkan poin-poin yang ada di APA yang mana golongan LGBT diserahkan pada adat lokal, oleh karena itu LGBT di negara Indonesia termasuk perilaku abnormal. Maka, dalam tatanan kenegaraan tidak dapat mengakomodir keberadaan perilaku LGBT. ${ }^{17}$

Komnas HAM juga berpandangan bahwa masih banyaknya kaum LGBT yang mendapatkan perlakuan diskriminasi dalam hal pekerjaan, layanan Kesehatan, layanan umum, dan lain sebagainya. Namun, menurut penulis hal tersebut tidak beralasan sama sekali. Buktinya dalam pendidikan kaum LGBT masih banyak yang diterima di Lembaga-lembaga edukasi baik swasta maupun negeri. Pun dengan pekerjaan dan layanan umum, mereka masih memiliki persamaan hak seperti yang dimiliki manusia umumnya. Dalam kenyataanya, hak asasi manusia kaum LGBT yang berkaitan dengan kebutuhan hidup masih diakui kecuali dalam aspek orientasi seksualnya yang membahayakan bagi diri mereka sendiri, mengganggu ketertiban dan dapat menyebabkan musnahnya keturunan manusia.

\section{Lesbian Gay Biseksual dan Transgender Sudut Pandang Hak Asasi Manusia Internasional}

Menurut Bassam Tibi yang mengatakan HAM merupakan hak-hak perseorangan yang tumbuh dari pemikiran modern Eropa tentang natural law (hukum alam). Hak-hak itu diciptakan oleh negara-negara di Eropa yang menjadi standarisasi lembaga hukum. Pada tahun 1948, hal tersebut yang menjadi cikal bakal Deklarasi Universal tentang Hak-hak Asasi Manusia (DUHAM)

${ }^{17}$ Elga Andina, “Faktor Psikososial Dalam Interaksi Masyarakat Dengan Gerakan LGBT di Indonesia”, dalam Jurnal Pusat Penelitian Badan Keahlian DPR RI, 183 (2016) 
PBB, yang kemudian menjadikan HAM sebagai hukum Internasional. ${ }^{18}$ Di tahun 2011 pada bulan Juni, Afrika Selatan yang mempunyai perwakilan di Dewan PBB menawarkan resolusi PBB untuk pertama kalinya sebagai HAM yang ditujukan khusus untuk identitas gender dan orientasi seksual. Hal tersebut mendapat persetujuan dari sebagian kecil mayoritas dan dukungan dari anggota Dewan semua wilayah. Resolusi inilah yang menjadi awal pembuka jalan untuk masalah yang berkaitan.

Banyak negara Islam yang masih merasa sulit untuk memahami masalah tersebut. Seharusnya topik seperti itu tidak mempunyai status sebagai subjek dalam hak asasi manusia internasional menurut anggapan negara-negara organisasi Islam. Permasalahan itu menunjukkan betapa sulitnya mengembangkan suatu hukum yang universal dan harmonis bagi badan supranasional, saat nilai-nilai dan adat istiadat menjadi ambigu melalui budayabudaya.

Menurut pandangan penulis, PBB sebagai representasi negara-negara di dunia seharusnya mempertimbangkan juga keberatan mayoritas Dewan PBB dari negara-negara lain yang pada dasarnya lebih banyak yang menolak resolusi tersebut daripada yang menerimanya. Namun, hal tersebut tidaklah mungkin terjadi jika dalam pemutusan resolusi lebih banyak ditentukan oleh isu-isu politik internasional. Termasuk dalam hal ini adalah United Nations Development Program (UNDP) yang sebagai organisasi internasional di bawah PBB yang dengan nyata-nyata sangat mendukung gerakan LGBT (LGBT movement) baik dengan dukungan moril maupun materil.

UNDP telah berafiliasi dengan beberapa negara yang mendukung gerakan LGBT. Termasuk di Indonesia terdapat wadah komunitas LGBT Indonesia (LGBTI) yang di bawah naungan organisasi UNDP Asia Tenggara. LGBT Indonesia juga mendapat dukungan dari UNDP yang melakukan kerjasama dengan USAID dan Kedutaan Swedia di Bangkok, Thailand. Empat negara yaitu Indonesia, Filipina, Thailand dan China mendapatkan dana kucuran dengan besaran US\$ 8 juta (sekitar RP 108 miliar). UNDP menyatakan bahwa hal tersebut adalah kerjasama dengan orang sipil yang tentunya melibatkan Lembaga-lembaga regional dan nasional dalam menegakkan hukum dan sumber daya manusia. Penulis sangat menyayangkan hal ini, kenapa pemerintah Indonesia meskipun secara eksplisit tidak mengakui dan melegalkan gerakan LGBT hanya berdiam diri dan tidak melakukan penegakan hukum yang seharusnya dilakukan demi norma-norma

18 Bassam Tibi, "Islamic Law/Syariah and Human Rights: International Law and International Relations" dalam Tori Lindholm and Kari Vogt (eds.), Islamic Law Reform and Human Rights: Challenges and Rejoinders, Oslo: Nordic Human Rights Publications, 75 (1993) 
agama dan kesusilaan yang sudah tertera pada Undang-Undang Republik Indonesia Tahun 1945.

Pada dasarnya secara universal LGBT sendiri tidak mempunyai legalitas internasional. Menurut penulis gerakan LGBT ini hanya merupakan sebuah upaya internasional untuk melanggengkan eksistensi politik internasionalnya. Bisa kita tengok negara Brazil yang notabene adalah negara simbol umat Nasrani dengan ditandai adanya patung Yesus terbesar yang selama puluhan tahun memegang tradisi agama dengan sangat kuat pun pada akhirnya runtuh dan tidak kuasa menolak gerakan LGBT. ${ }^{19} \mathrm{Hal}$ ini menunjukkan betapa sangat kuatnya ekspansi dan pengaruh dari LGBT movement tersebut.

Jika kita menilik dalam 30 hak-hak manusia yang diatur pada Deklarasi Universal Hak Asasi Manusia, tak satupun yang menyebutkan secara khusus tentang kaum LGBT ini. Justeru dalam Deklarasi Universal Hak Asasi Manusia yang ke 16 tersebut disebutkan tentang hak berkeluarga dan menikah. Setiap manusia dewasa mempunyai hak untuk kawin dan mempunyai keluarga bila mereka ingin. Laki-laki dan perempuan mempunyai persamaan hak waktu mereka kawin, dan waktu mereka berpisah. ${ }^{20}$ Jika merujuk pada HAM Internasional tersebut, maka dapat kita pahami bahwa seandainya LGBT diakui dan legal maka pada tahun 1948 sebagai lahirnya HAM Internasional tidak hanya menyebutkan pria dan wanita sebagai pasangan tetapi juga disebutkan pasangan sejenis. Hal inilah yang kemudian menurut penulis dapat dijadikan sebagai argumentasi hukum internasional dalam menolak dan melarang gerakan LGBT tersebut.

\section{Simpulan}

HAM Nasional dan hukum positif Indonesia tidak secara jelas mendukung maupun melegalkan gerakan LGBT. Justru di dalam Undang-Undang Republik Indonesia Tahun 1945 dan Undang-Undang Nomor 39 Tahun 1999 tentang HAM menjelaskan bahwa HAM seseorang tidak boleh melampau batas yang artinya mempunyai batasan-batasan yang tidak melanggar kesusilaan, norma agama dan ketertiban nasional. Pun termasuk aturan HAM Internasional tak ada

${ }^{19}$ Dikutip dalam wawancara dengan Bapak Dr. H. Maneger Nasution, M.Ag (Wakil Ketua Komisi Hukum dan Perundang-undangan Majelis Ulama Indonesia) pada tanggal 5 Juni 2020

${ }^{20}$ Lihat 30 Hak Asasi Manusia yang tertulis dan disepakati dalam Deklarasi Universal Hak Asasi Manusia 
satupun yang menyatakan dukungan dan pelegalan gerakan LGBT. Pengakuan orientasi sesksual LGBT hanya dilakukan oleh UNDP yang notabene adalah organisasi politik internasional dibawah PBB. Dan dalam Deklarasi Universal HAM Internasional yang merupakan sebuah pengakuan tentang HAM manusia seluruhnya pun tidak disebutkan hubungan sesame jenis melainkan hanya ada hubungan antara pria dan wanita.

\section{Saran}

Pro kontra tentang gerakan LGBT menurut penulis sudah tidak perlu diperdebatkan lagi. Karena secara normatif sudah dapat dilihat dalam aturanaturan HAM Nasional maupun HAM Internasional. Untuk menegakkan supremasi hukum demi tercapainya ketertiban nasional dan internasional, maka baik pemerintah Indonesia maupun PBB sudah saatnya mengembalikan permasalahan LGBT ini kepada asas-asas yang sudah disepakati dalam UndangUndang Republik Indonesia Tahun 1945 dan Deklarasi Universal Hak Asasi Manusia.

\section{Daftar Pustaka}

Buku

Amiruddin dan H. Zainal Asikin, Pengantar Metode Penelitian Hukum, PT. Raja Grafindo Persada, Jakarta, 2004.

A. Widada Gunakaya S.A, Hukum Hak Asasi Manusia, ANDI, Yogyakarta, 2017.

Bassam Tibi, “Islamic Law/Syariah and Human Rights: International Law and International Relations" dalam Tori Lindholm and Kari Vogt (eds.), Islamic Law Reform and Human Rights: Challenges and Rejoinders, Oslo: Nordic Human Rights Publications, 1993.

Eko Riyadi, Hukum Hak Asasi Manusia Perspektif Internasional, Regional dan Nasional, PT. Raja Grafindo Persada, Depok, 2018.

A. Masyhur Effendi, Hak Asasi Manusia Dalam Hukum Nasional dan Internasional, Ghalia Indonesia, Bogor, 1993.

Harkristuti Harkrisnowo, Hukum dan Hak Asasi Manusia, Universitas Terbuka, Tangerang Selatan, 2015.

Manfred Nowak, Introduction to The International Human Rights Regime, Martinus Nijhoff Publishers, Leiden, 2003.

Scott Davidson, Hak Asasi Manusia, Pustaka Utama Grafiti, Jakarta, 2008.

Soerjono Soekanto, Pengantar Penelitian Hukum, UI Press, Jakarta, 1982. 
Suharsini Arikunto, Manajemen Penelitian, PT Rineka Cipta, Jakarta, 1993.

Todung Mulya Lubis, Hak-Hak Asasi Manusia Dalam Masyarakat Dunia, Yayasan Obor Indonesia, 1993.

Jurnal

Elga Andina, "Faktor Psikososial Dalam Interaksi Masyarakat Dengan Gerakan LGBT di Indonesia", dalam Jurnal Pusat Penelitian Badan Keahlian DPR RI, 183 (2016).

Komisi Nasional Hak Asasi Manusia, Prinsip-Prinsip Pemberlakuan Hukum HAM Internasional Dalam Kaitannya Dengan Orientasi Seksual dan Identitas Jender, Komnas HAM, Jakarta, 2015.

Meilanny Budiarti Santoso, “LGBT Dalam Perspektif HAM”, dalam jurnal Share Social Work Journal, 229 (2016).

Fatwa MUI Tentang Nomor 57 Tahun 2014 Tentang Lesbian, Gay, Sodomi dan Pencabulan, diakses dari internet pada tanggal 16 Juli 2020 pukul 8.38. 